\title{
Map updating and coastline control with very high resolution satellite images: application to Molise and Puglia coasts (Italy)
}

\author{
Eleonora Bertacchini and Alessandro Capra \\ DIMeC - Department of Mechanical and Civil Engineering, University of Modena and Reggio Emilia, \\ Via Vignolese 905, 41125 - Modena, Italy. E-mail: eleonora.bertacchini@unimore.it
}

\begin{abstract}
The very high-resolution satellite images are a useful tool both for map updating and environmental monitoring. Phenomena, with a detail of $0.5 \mathrm{~m}$ up to $1 \mathrm{~m}$, could be observed. The coastal areas are quite critical and quickly evolving. QuickBird and Ikonos images are likely able to investigate coastal changes within $1 \mathrm{~m}$ of accuracy. This paper deals with two experiments applied to the coastline control: the first one concerns the study of Molise coasts, while the second is related to the Puglia Region map updating.
\end{abstract}

Keywords: Ikonos, QuickBird, orthorectification, satellite images, map updating.

Immagini satellitari ad alta risoluzione per l'aggiornamento cartografico e per il controllo della linea di costa. Applicazione alla costa del Molise e della Puglia (Italia)

\section{Riassunto}

Le immagini satellitari ad alta risoluzione si prestano ad effettuare un aggiornamento cartografico che è buon pre-requisito per effettuare operazioni di controllo e monitoraggio di fenomeni rilevabili con grado di dettaglio da $0.5 \mathrm{~m}$ a $1 \mathrm{~m}$. Le zone costiere sono aree abbastanza critiche e in continua evoluzione e immagini QuickBird o Ikonos hanno caratteristiche tali da poter indagarne le trasformazioni di entità dell'ordine del metro. A titolo si esempio vengono presentate due esperienze applicative per il controllo della linea di costa. La prima riguarda lo studio costiero della Regione Molise, mentre la seconda, l'analisi di immagini della Regione Puglia, ed è inerente alla valutazione di sistemi per l'aggiornamento cartografico.

Parole chiave: Ikonos, QuickBird, ortorettifica, immagini satellitari, aggiornamento cartografico.

\section{Introduction}

The High and Very High space Resolution sensors (VHR) outline new monitoring and cartographic challenges on cartographic design and end-product quality control.

This paper deals with the study of the orthorectification process based on QuickBird and Ikonos satellite images, paying particular attention to the analysis of geometric mechanism. The final purpose is the production of cartography at medium and large scale by means of 


\section{VHR images.}

The Very High Spatial Resolution satellite images (Panchromatic QuickBird SR=0.6 m and Ikonos $\mathrm{SR}=1 \mathrm{~m}$ ) allows the generation of maps both at large and detailed scale. Thus the interest in new VHR images quickly increases and sometimes results in the substitution of traditional aerial photogrammetry.

Ikonos and QuickBird satellite images allow a significant quality in map displaying, supporting geopositioning within an accuracy of $1 \mathrm{~m}$ and topographic mapping at 1:10000 scale or even larger. [Fraser et al., 2001; Pérez-Gutierréz and Sánchez, 2007].

Orthorectification of both panchromatic QuickBird Basic Imagery and Ikonos Ortho Ready one, will be presented in the following. The purpose is to test several othorectification methods in order to suggest a standard procedure for map updating and environmental monitoring, particularly useful for Public Administrations and Civil Protection. They need to manage with products which are at the same time reliable, effective, operating and economic. The last request may take advantage from the existing databases of territorial information. First of all, very high resolution images, such as QuickBird or Ikonos, have to be geometrically processed with suitable GCPs (Ground Control Points) and DTMs (Digital Terrain Model) in order to generate precise map products. Then they can be used for geospatial information extraction. The process itself is affected by several error sources, such as the indetermination in image points identification, the errors in GCPs coordinates, the possible low accuracy of the DTM, etc. All those factors influence the resulting quality and must be carefully taken into account.

The paper consists of two parts. Firstly, a description of the Ikonos image orthorectification, whose test site is located in the Molise Region (Italy) [Bertacchini et al., 2007]. Secondly the QuickBird image potentiality has been investigated in two different areas of the Puglia Region (Italy) [Bertacchini et al., 2009]. The orthorectification main task is the correction, or at least the reduction, of acquisition errors with the aim to obtain an image product comparable to a map. The whole orthorectification procedure has been analyzed in order to evaluate the error propagation by means of several dataset characterized by different accuracy. The analysis of Molise image is included in the project called "NOE-Patrimonio e prevenzione dai rischi naturali", which follows the European Community guidelines for the Integrated Coastal Zone Management (ICZM). The work results from the cooperation of the University of Modena and Reggio Emilia, ENEA ("Agenzia nazionale per le nuove tecnologie, l'energia e lo sviluppo economico sostenibile") and the Molise Region. Concerning the Puglia images, the research is related to the project "Sistema Informativo Territoriale", whose purpose is the creation of a Geographic Information System (GIS) about the local territory (regional scale), according to the IntesaGIS policy. It consists of different products including a 3D topographic database of Puglia Region at 1:5000 scale. This is the result of a collaboration between the University of Modena and Reggio Emilia and InnovaPuglia, which is the Institution taking care of the GIS generation and updating. The potentiality of VHR satellite images orthorectification was deeply analyzed in our research. The main goal was the analysis of such orthorectification process for map updating and coastline monitoring. VHR images are likely able to investigate coastal changes within $1 \mathrm{~m}$ of accuracy. Results, obtained by means of several dataset and different investigation methodologies, showed that the orthorectified-image accuracy and precision depend on the dataset and that it was very difficult to reach $1 \mathrm{~m}$ of accuracy. 


\section{Study site and data set}

\section{Study site}

As mentioned above, the test sites are located in two Italian Regions: Molise and Puglia. All the areas of interest are morphologically various and complex, with a heterogeneous territory consisting of sea, coast, hills, mountains, urban and residential sites (see Fig. 1, Fig. 2 and Fig. 3). The sea covers most of the images, especially for Molise's scene, because the sites were chosen by the coast in order to focus on coastline monitoring. The Molise scene extends between Trigno and Biferno rivers, while Puglia images cover Gargano (around Peschici) and Salento (around Otranto) areas.

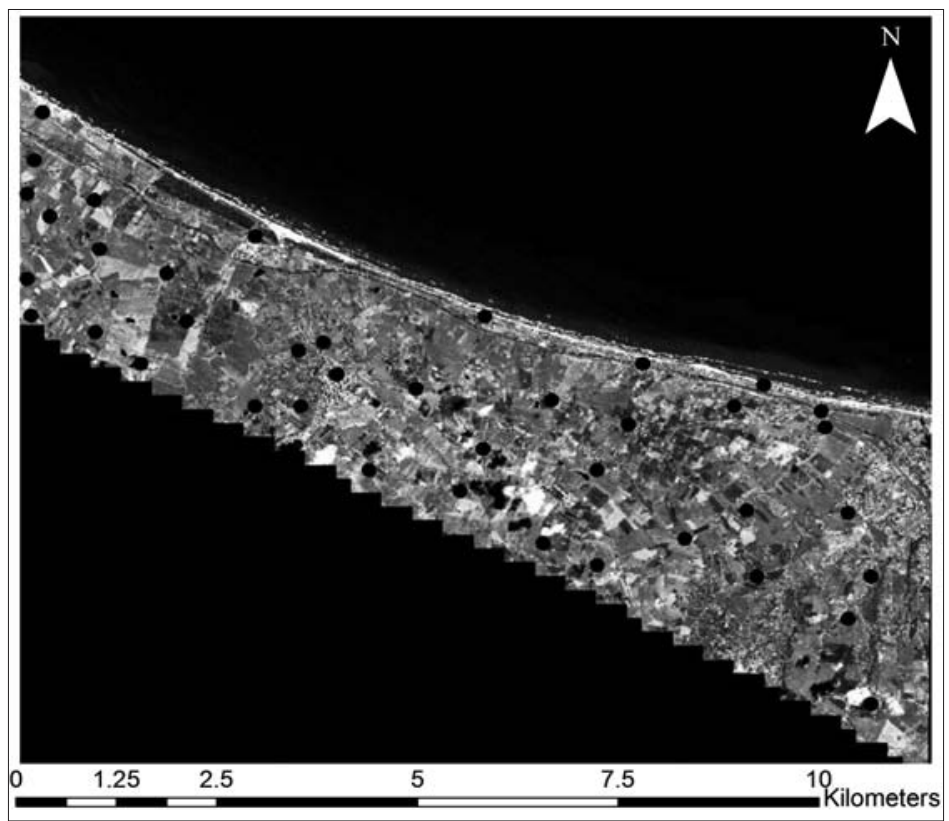

Figure 1 - Molise. Distribution of GCPs on the image.

\section{Data set}

\section{Images}

The test procedure was carried out with VHR images: QuickBird (Puglia) and Ikonos (Molise). Table 1 shows the main features of such images, summarizing the image type, the localization, the acquisition date, the off nadir viewing angle and the spatial resolution.

QuickBird images are available in the raw data format, Basic Imagery, preserving the satellite geometry. This data format is preferred to achieve high accuracy geometric correction and geospatial products. Thus, a rigorous sensor model can be parameterized by the user thanks to a complete set of image acquisition metadata including several information: camera timing, alignment and focal plane layout and a full set of satellite attitude and ephemerides spanning the imaging window. Users require this metadata in order to orthorectify satellite images and provide the most accurate and complete geolocation data [Cheng et al., 2003; Robertson, 2003]. 
Ikonos image is at Geo Ortho kit level. It preserves the satellite geometry and provides a complete set of image acquisition metadata allowing users to parameterize a rigorous sensor model too. Images at Geo Ortho kit level requires a higher number of GCPs than that needed at the raw level, because images have been previously managed. Despite that, a modest amount of about 20-25 GCPs is sufficient [Fraser et al., 2001].

Both Ikonos and QuickBird scenes are archive images, but one of the QuickBird images has no proper characteristics for orthorectification because the off nadir angle is more than $8^{\circ}$ (see Tab. 1). All resulting products depend on the GCPs coordinates accuracy. In this case the UTM WGS84 coordinate system was chosen for the computation. The use of UTM WGS84 coordinate system allows us to concentrate on orthorectification, avoiding coordinate system and datum transformation errors.

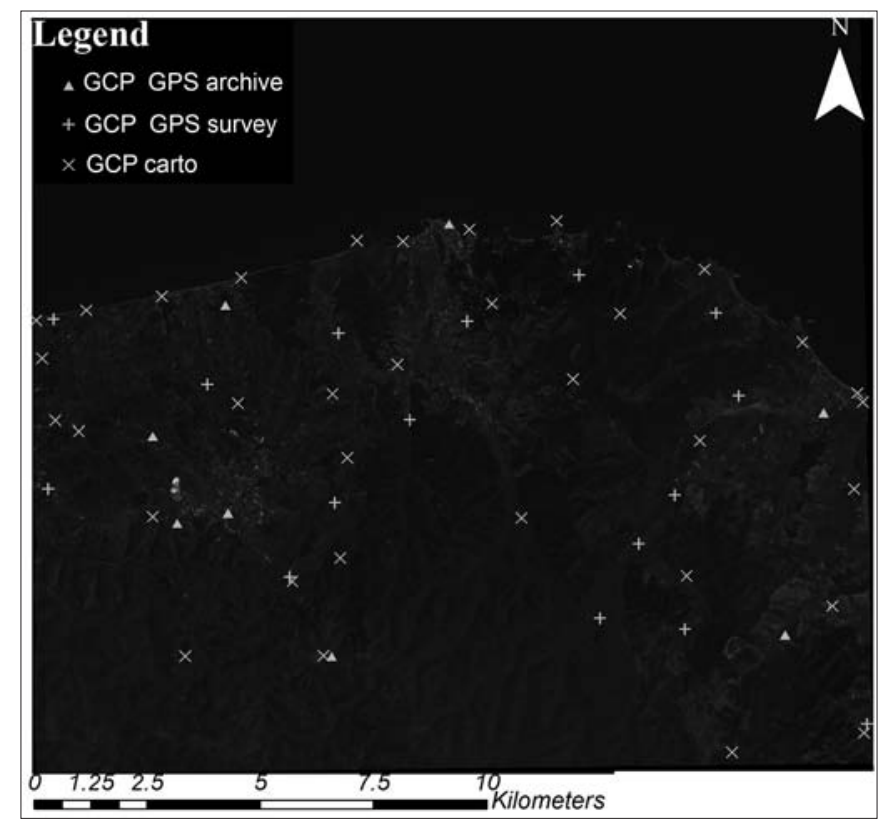

Figure 2 - Gargano, Puglia. Distribution of GCPs on the image.

\section{Ground Control Points}

The number of GCPs required in the orthorectification analysis, depends on different conditions: the method of collection, the sensor type and resolution, the image spacing, the study site, the physical environment, the mathematical model, the GCPs definition and accuracy and the final expected accuracy. Whenever GCPs are determined a priori, without any knowledge of the images to be processed, about $50 \%$ of the points may be rejected. If GCPs are properly determined a posteriori, after a deep analysis of the images, the rejection factor is smaller (20-30\%). Therefore, the GCPs collection step is very important in the image processing procedure. The increase of the number of GCPs allows the reduction of the 3D physical models error propagation [Fraser et al., 2001; Toutin, 2004b].

At least 30 GCPs for each image has been collected in order to completely and uniformly cover 
the whole area of interest. Particular attention has been paid to their location, that is as much as possible a homogeneous distribution within the image extension in order to provide an external reference for horizontal positions and heights.

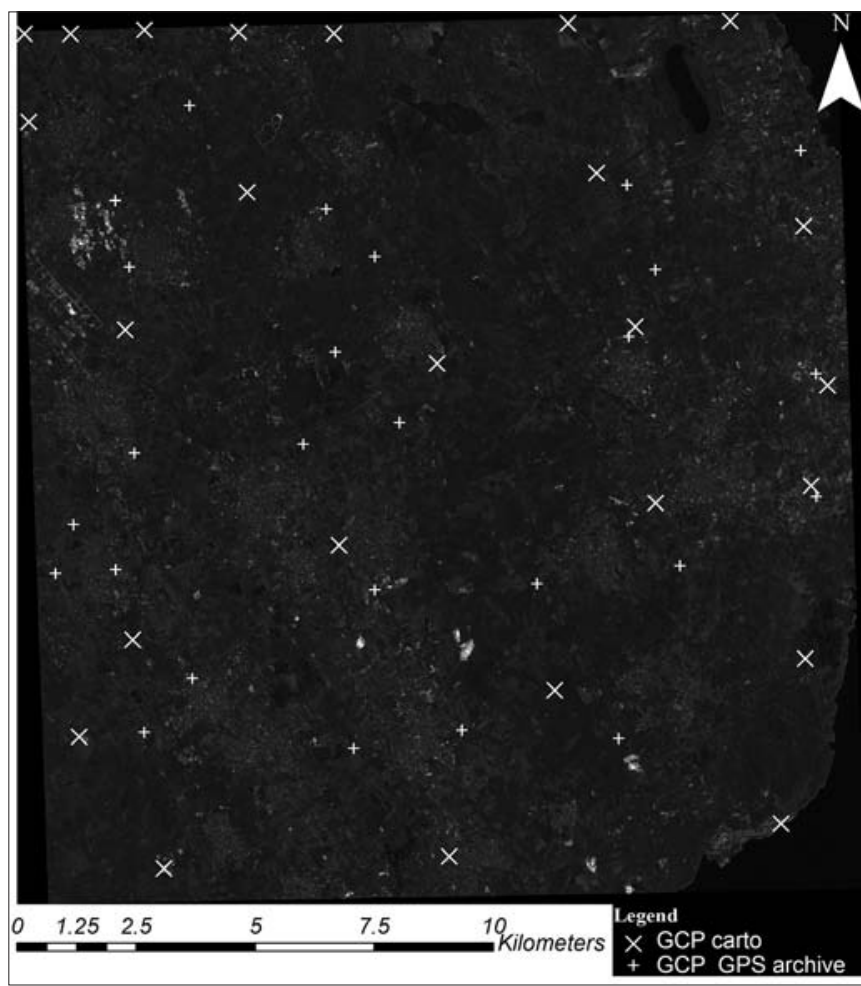

Figure 3 - Salento, Puglia. Distribution of GCPs on the image.

Table 1 - Main characteristics of images.

\begin{tabular}{|c|c|c|c|}
\hline Ikonos - Molise & $\begin{array}{c}\text { QuickBird } \\
\text { Gargano, Puglia }\end{array}$ & $\begin{array}{c}\text { QuickBird } \\
\text { Salento, Puglia }\end{array}$ \\
\hline Acquisition date & $23 / 04 / 2004$ & $28 / 07 / 2007$ & $8 / 07 / 2007$ \\
\hline Image type & $\begin{array}{c}\text { Ikonos } \\
\text { Geo Ortho kit }\end{array}$ & $\begin{array}{c}\text { QuickBird } \\
\text { Basic }\end{array}$ & $\begin{array}{c}\text { QuickBird } \\
\text { Basic }\end{array}$ \\
\hline Off nadir angle & $8.0^{\circ}$ & $16.6^{\circ}$ & $8.8^{\circ}$ \\
\hline SR & $1 \mathrm{~m}$ & $0.6 \mathrm{~m}$ & $0.6 \mathrm{~m}$ \\
\hline
\end{tabular}

GCPs coordinates result both from cartography extraction and some scheduled GPS (Global Positioning System) surveys: the first method allows the knowledge of GCPs with an accuracy of about $1 \mathrm{~m}$ when maps at 1:5000 scale are used; whereas the second approach provides a centimeter level of accuracy resulting both from static and real time kinematic surveys. Therefore, despite their different order of magnitude, all GCPs have the proper accuracy for achieving the purpose of this job: the investigation of coastlines within $1 \mathrm{~m}$ of 
changes. Several dataset with different quality allow to suggest the most useful procedure for the orthorectification of a large amount of images.

The more accurate GCPs coordinates are, the lower is the required number for a successful modeling. But, when their accuracy is worse, more GCPs should be known, depending on the final accuracy target [Toutin, 2001]. GCPs coordinates from GPS surveys are for sure more precise than those derived from cartography but, at the same time, they require more time and people to obtain results with an accuracy which is even higher that the needed one. Thus, the cartography approach seems to be more productive because it allows the extraction of more GCPs in a shorter time with a sufficient accuracy, too: map pointing accuracy within $1 \mathrm{~m}$, by means of maps at 1:5000 scale. The most suitable and useful strategy for identifying and locating points on the image is based on choosing elements which strongly contrast with their background. Concerning the GPS approach for reference coordinates detection, GCPs were mainly chosen nearby artificial artifacts, with an image pointing accuracy lower than 1 pixel. The identified sites were planned to be surveyed in a static mode for Molise test site; while for the Puglia areas were collected by RTK (Real Time Kinematic) GPS techniques [Baiocchi et al., 2006; Dominici et al., 2006].

Field operations carried out in Molise were studied and designed in order to achieve the best accuracy in resulting coordinates. Those GCPs have been digitized nominally to half pixel precision and, as expected, the care taken in the whole process allowed to successfully use quite all of them for subsequent steps.

Puglia test is characterized by a lot of GCPs with multiple origin: some were collected by cartography (maps at 1:5000 scale), some result from specifically scheduled GPS surveys and some others were simply taken from the regional geographic database and result from previous GPS surveys (2006) planned for airborne photogrammetry applications ("archive" points). In details, concerning the Gargano area only 9 of 25 available "archive" points were reliable and useful. Anyway they were not sufficient to orthorectify the image, thus 13 more GCPs (11 of them were actually used) were scheduled to be surveyed in RTK mode while 32 further points were collected by cartography with $1 \mathrm{~m}$ of accuracy. Concerning the Salento test site, no more GPS surveys were required because the regional database, richer about this area, provided a sufficient number of reliable "archive" points (27 of 50 available GCPs); 24 additional GCPs were extracted from cartography with $1 \mathrm{~m}$ of accuracy.

The distribution of GCPs on each image is shown in Figure 1, Figure 2 and Figure 3. Table 2 summarizes origin, characteristics and accuracy of GCPs.

\section{Digital Elevation Models}

Molise Region supplied a low Spatial Resolution ( $\mathrm{SR}=40 \mathrm{~m})$ DTM with an expected accuracy of $10 \mathrm{~m}$ in height. The Puglia Pubblic Administration provided a high Spatial Resolution ( $\mathrm{SR}=8 \mathrm{~m}$ ) DTM with a $2 \mathrm{~m}$ accuracy in height, allowing for a more accurate geo-referencing.

\section{Procedure and experimental results}

In order to assess the performance of orthorectification, two dataset consisting of QuickBird (with panchromatic geometric resolution of $0.6 \mathrm{~m}$ ) and Ikonos (with panchromatic geometric resolution of $1 \mathrm{~m}$ ) images have been analyzed together with the associated control points over Puglia and Molise coasts, respectively. 
Table 2 - Number, origin and quality of GCPs for each image.

\begin{tabular}{|c|c|c|c|c|c|c|}
\hline & \multicolumn{2}{|c|}{$\begin{array}{c}\text { GCPs } \\
\text { Ikonos - Molise }\end{array}$} & \multicolumn{2}{|c|}{$\begin{array}{c}\text { GCPs } \\
\text { QuickBird } \\
\text { Gargano, Puglia }\end{array}$} & \multicolumn{2}{|c|}{$\begin{array}{c}\text { GCPs } \\
\text { QuickBird } \\
\text { Salento, Puglia }\end{array}$} \\
\hline & Number & Accuracy & Number & Accuracy & Number & Accuracy \\
\hline \multirow{2}{*}{ GPS survey } & \multirow{2}{*}{$\begin{array}{c}41 \\
\text { (39 used) }\end{array}$} & \multirow{2}{*}{$2-3 \mathrm{~cm}$} & $\begin{array}{c}13 \\
\text { (11 used) }\end{array}$ & $2-3 \mathrm{~cm}$ & \multirow{2}{*}{$\begin{array}{c}27 \\
\text { (archive) }\end{array}$} & \multirow{2}{*}{$4-5 \mathrm{~cm}$} \\
\hline & & & 9 (archive) & $4-5 \mathrm{~cm}$ & & \\
\hline $\begin{array}{l}\text { Cartography } \\
\text { (1:5.000 scale) }\end{array}$ & -- & $1 \mathrm{~m}$ & 32 & $1 \mathrm{~m}$ & $\begin{array}{c}24 \\
\text { (23 used) }\end{array}$ & $1 \mathrm{~m}$ \\
\hline Total number & \multicolumn{2}{|c|}{39} & \multicolumn{2}{|c|}{52} & \multicolumn{2}{|c|}{50} \\
\hline
\end{tabular}

The process began with the computation of the mathematical models, then the orthorectification through DTMs was performed. Finally, the geometric accuracy of the mathematical model and of the generated orthoimages can be evaluated by means of a qualitative and quantitative control.

For the orthorectification process two mathematical models are usually chosen [Toutin, 2004a, 2004b; Fraser et al., 2000]:

1) the rigorous or physical model with the drawback of requiring information about the acquisition system;

2) the empirical model which is used when no information are provided about the acquisition system; its accuracy and robustness depend on the distribution and accuracy of the ground control points.

For the Ikonos image orthorectification the DLT (Direct Linear Transformation) empirical model, implemented in the Micromap software (v. 1.1), has been tested [Fraser et al., 2001; Fraser and Yamakawa, 2004]. QuickBird images have been processed with the rigorous model implemented in the Orthoengine module of the PCI Geomatic software (v. 10.1).

The final geometric precision of the resulting orthorectified image was checked from different points of view, namely:

1) verification of the procedure itself by control statistics that are usually applied to the GCPs (internal orientation error);

2) comparison between the resulting orthoimage and cartography at a suitable scale (qualitative control);

3) verification of the image/terrain CPs position using coordinates obtained by GPS methods or derived from cartography (1:5.000 map scale) (statistic quantitative control).

First of all, the quality control of the orthoimage was operated in order to evaluate if the resulting accuracy was approximately within one meter (Fig. 4, Fig. 5, Fig. 6); this step aimed to check the overlapping between the orthoimage and the cartography at 1:5000 scale. Different areas of the images were explored both on the land and on the coast, in order to find differences in results between plain and hill zones. When this check was overcome, the quantity control could start and was carried out by means of GCPs/CPs with the purpose of exploring and investigating the two geometric modeling techniques used for geolocation and geocorrection of QuickBird and Ikonos imagery. 


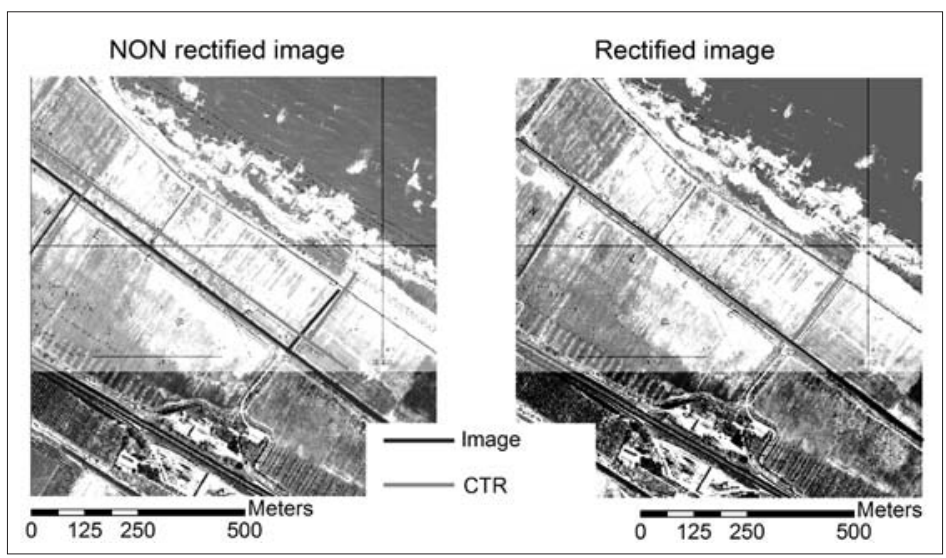

Figure 4 - Molise. Overlapping between image and cartography. Non rectified image: roads don't overlap; rectified images: elements coincide.

A set of GCPs was extracted from the available ones to be used in the mathematical model; the remaining points were partially used as CPs to test the mathematical model itself (internal orientation error), while the very last left GCPs were employed as CPs for the final orthorectified images assessment. Table 3 presents these results, while Figure 7 and Figure 8 show the trend of the mathematical model errors of orthorectified images, in terms of standard deviation error $(\mathrm{m})$ both in $x$ and $y$ directions, for Molise and Gargano test sites.

Accuracy, sometimes read in the literature, can not always be achieved for Puglia and Molise test, even if QuickBird orthorectified images was more accurate than Ikonos one. The orthorectification process is very sensitive to the data quality and to the morphology of the area [Grodecki and Dial, 2001; Cheng et al., 2003; Dial and Grodecki, 2003; Robertson, 2003; Pérez-Gutierréz and Sánchez, 2007].

Results shown in the literature, illustrates that it is possible to get geometric pixel accuracy ( $\mathrm{SR}=0.6 \mathrm{~m}$ for QuickBird or $\mathrm{SR}=1 \mathrm{~m}$ for Ikonos images) with the rigorous mathematical models, with a small number of GCPs (less than 10) if data quality is excellent and imaging geometry is favorable. The same conclusions can be drawn for the DLT model, even if more GCPs are required [Fraser et al., 2001, 2002]. When the morphology of the area is quite various, the sea covers a part of the scene, the image is largely distorted and the DTM has a bad quality, many more GCPs are needed and the final orthoimage results according to 1:10000 scale map (2 $\mathrm{m}$ of accuracy). Therefore, accuracies between 0.5 and 2 pixels are more commonly encountered in practical tests: standard deviation errors listed in Table 3 confirm this statement for QuickBird images, while the Ikonos one presents very bad results.

Ikonos image quality, after orthorectification, is noticeably lower than the QuickBird resulting one. This is probably due to the synergy of several factors: the computation of an empirical/statistical model, the larger presence of the sea, the poor set or even worse the absence of data on the scene, the consequent bad distribution of GCPs over the whole scene and the very low spatial resolution of the DTM. 

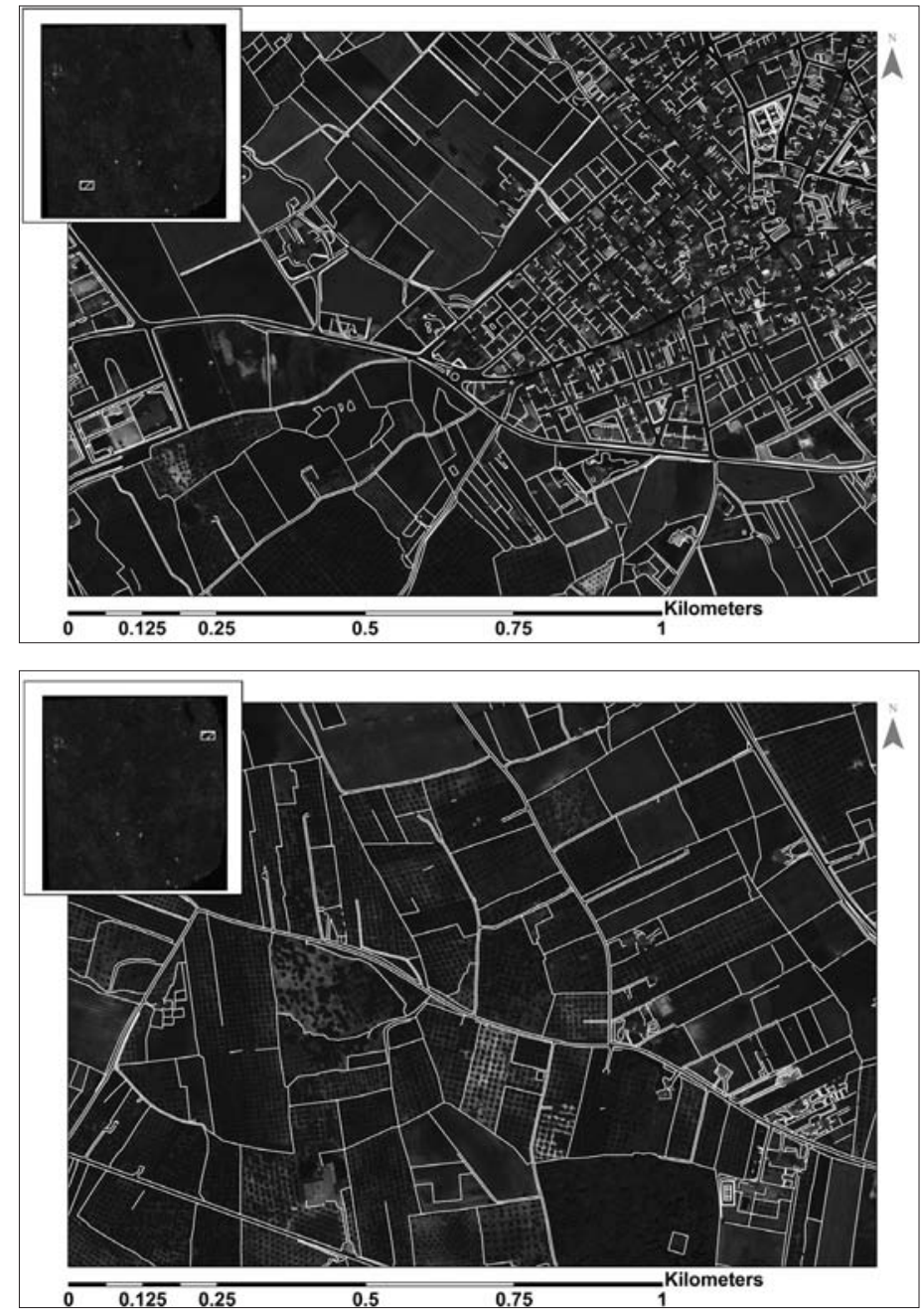

Figure 5 - Puglia, Salento. Overlapping between image and cartography over different zones.

\section{Conclusions and future developments}

Potentially, the Very High Resolution satellite images are a useful tool both for map updating, monitoring and control of phenomena which can be observed with a detail ranging from 0.5 $\mathrm{m}$ up to $1 \mathrm{~m}$. Such an example is the coastline changing. Coastal areas are quite critical and quickly evolving, thus QuickBird and Ikonos images are likely able to investigate coastal variations within $1 \mathrm{~m}$ of magnitude.

In practice, the accuracy of orthorectified images seems to be strictly linked to the data quality: the Puglia dataset analysis showed how a high accuracy DTM together with a proper number of GCPs (about 20), whether directly surveyed or extracted from cartography, allowed a good orthorectification, even in the case of images with high off-nadir viewing angles. 

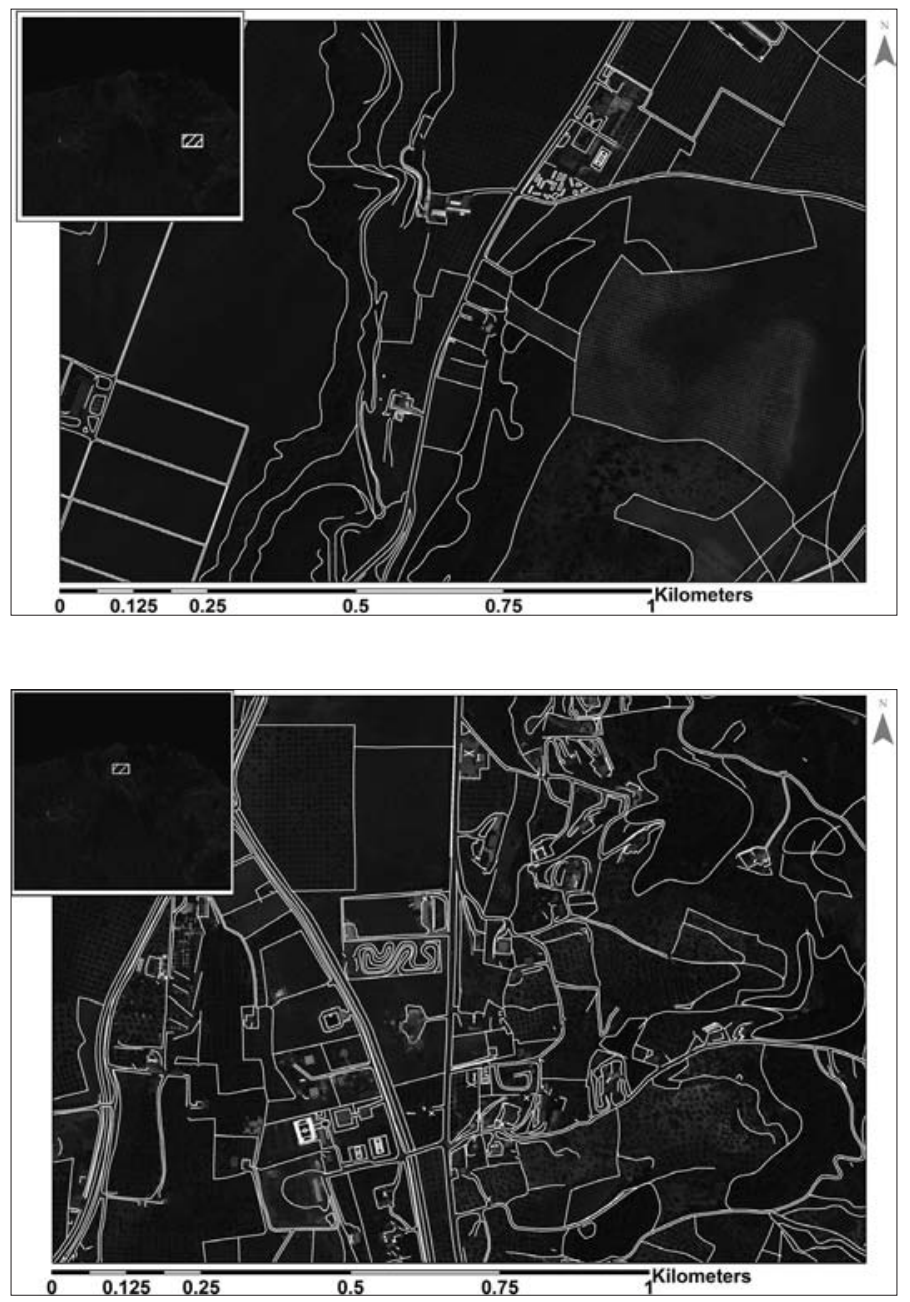

Figure 6 - Puglia, Gargano. Overlapping between image and cartography over different zones.

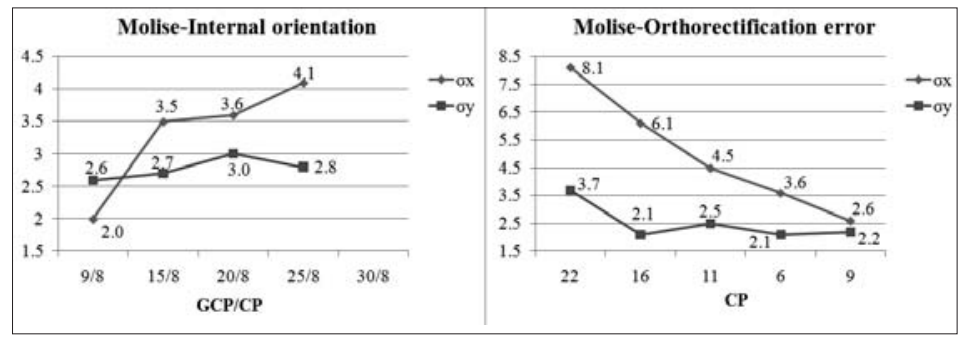

Figure 7 - Molise. Internal orientation error (left) and orthorectification error (right). All values are standard deviation error values expressed in meters. 


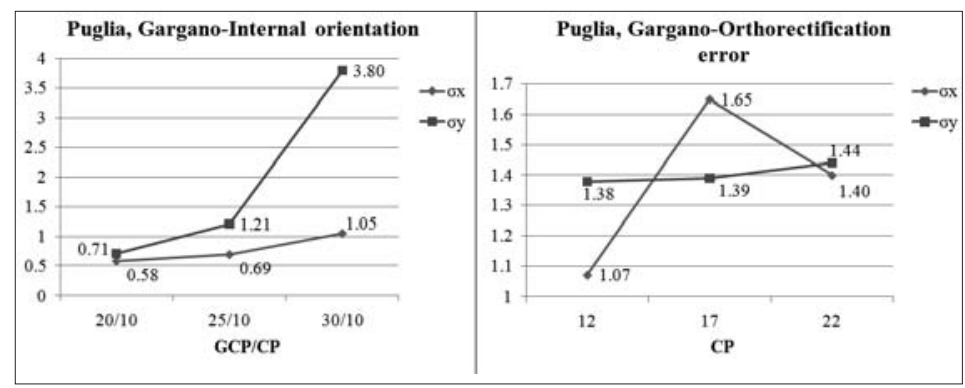

Figure 8 - Puglia, Gargano. Internal orientation error (left) and orthorectification error (right). All values are standard deviation error values expressed in meters.

Table 3 - Standard deviation error (m) of mathematical model and of orthorectification results.

\begin{tabular}{|c|c|c|c|c|c|c|}
\hline & \multicolumn{3}{|c|}{ Mathematical model } & \multicolumn{3}{|c|}{ Orthorectification } \\
\hline & \multirow[t]{2}{*}{ GCP/CP } & \multicolumn{2}{|c|}{$\begin{array}{c}\text { Standard deviation } \\
\text { error }(\mathbf{m})\end{array}$} & \multirow[t]{2}{*}{$\mathbf{C P}$} & \multicolumn{2}{|c|}{$\begin{array}{c}\text { Standard deviation } \\
\text { error }(\mathbf{m})\end{array}$} \\
\hline & & $\mathbf{X}$ & $\mathbf{Y}$ & & $\mathbf{X}$ & $\mathbf{Y}$ \\
\hline \multirow{2}{*}{$\begin{array}{c}\text { QuickBird } \\
\text { Salento, Puglia }\end{array}$} & $25 / 8$ & 0.42 & 0.72 & 17 & 1.53 & 1.49 \\
\hline & $20 / 8$ & 0.58 & 0.77 & 22 & 2.85 & 0.91 \\
\hline \multirow{3}{*}{$\begin{array}{c}\text { QuickBird } \\
\text { Gargano, Puglia }\end{array}$} & $30 / 10$ & 1.05 & 3.80 & 12 & 1.07 & 1.38 \\
\hline & $25 / 10$ & 0.69 & 1.21 & 17 & 1.65 & 1.39 \\
\hline & $20 / 10$ & 0.58 & 0.71 & 22 & 1.40 & 1.44 \\
\hline \multirow{5}{*}{$\begin{array}{l}\text { Ikonos, } \\
\text { Molise }\end{array}$} & $9 / 8$ & 2.0 & 2.6 & 22 & 8.1 & 3.7 \\
\hline & $15 / 8$ & 3.5 & 2.7 & 16 & 6.1 & 2.1 \\
\hline & $20 / 8$ & 3.6 & 3.0 & 11 & 4.5 & 2.5 \\
\hline & $25 / 8$ & 4.1 & 2.8 & 6 & 3.6 & 2.1 \\
\hline & $30 /--$ & --- & --- & 9 & 2.6 & 2.2 \\
\hline
\end{tabular}

Concerning Molise dataset, results confirmed that the error introduced by a low spatial resolution DTM can even be overcame neither by a very good quality nor by a great number of GCPs. The Molise test site is more challenging and suitable for the future developments of this research. Indeed, the new policy of Public Administrations in terms of cartography and DTM generation let the authors hope to handle higher quality data and new images in order to try several orthorectification computations with a better resulting accuracy. At present, the Italian Ministero dell'Ambiente provides a $20 \mathrm{~m}$ spatial resolution DTM which will be used soon to perform a new test. Currently, Public Administrations are supposed to update their maps and 3D terrestrial databases by means of the IntesaGIS policy. The analysis of the orthorectification process presented in this paper should be also meant and seen from this perspective. In term of costs-benefits, the cost of images covering a whole Region is probably not negligible. At the same time additional costs must be taken into account, such as for field operations and surveys, which are probably necessary, especially 
when a low resolution DTM and a bad geometry of the image are only available.

\section{Acknowledgements}

A special thank to Puglia and Molise Regions for their collaborations and data providing; to InnovaPuglia (Valenzano, Bari) for its "on site" support; to Francesco Immordino (ENEA, Bologna) for his technical and scientific support and to Giuliano Gallerini and Marco Labate (Leica Geosystems -Lodi) for their survey support.

\section{References}

Baiocchi, V., Betti, B., Carrion, D., Giannone, F., Tornatore F. (2006) - Orthorectification of a satellite EROS A1 Milan Image by GPS RTK control and check points: different models comparison. Bollettino SIFET, 4: 79-93.

Bertacchini E., Capra A., Dubbini M., Immordino F. (2007) - Ortorettifica di immagini satellitari Ikonos della costa del Molise attraverso il modello DLT. Proceedings of the Convegno Nazionale SIFET (CD rom).

Bertacchini E., Bellanova A., Capra A., Caroppo T. (2009) - Valutazione dell'utilizzo di immagini satellitari ad alta risoluzione QuickBird per l'aggiornamento del database topografico del SIT della Regione Puglia. Proceedings of Asita National conference (CD rom).

Cheng P., Toutin T., Zhang Y., Wood M. (2003) - QuickBird-Geometric correction, path and block processing and data fusion. Earth Observation Magazine.

Dial G., Grodecki J. (2003) - Applications of IKONOS Imagery. Proceedings of ASPRS Conference.

Dominici D., Feltrami G. M., De Girolamo P. (2006) - Ortorettifica di Immagini satellitari ad alta risoluzione finalizzata al monitoraggio costiero a scala regionale. Studi Costieri, 11: $145-146$.

Fraser C.S. (2000) - High-resolution satellite imagery: a review of metric aspects. Int. Arch. Photogramm. Remote Sens., 33: 452- 459.

Fraser C. S., Hanley H. B., Yamakawa T. (2001) - Geopositioning Accuracy of Ikonos Imagery: Indications from Two Dimensional Transformations. The Photogrammetric Record, 17: 317 - 329.

Fraser C. S., Hanley H. B., Yamakawa T. (2002) - Three Dimensional Geo-positioning accuracy of Ikonos Imagery. The Photogrammetric Record, 17: 465-479.

Fraser C. S., Yamakawa T. (2004) - Insight into the affine model for high resolution satellite sensor orientation. ISPRS Journal of Photogrammetry and Remote sensing, 58: 275288.

Grodecki J., Dial G. (2001) - Ikonos geometry accuracy. Proceedings of ISPRS Joint Workshop High Resolution from Space.

Pérez-Gutierréz C., Sánchez N. (2007) - Internal Approach of the geometric accuracy evaluation of some orthorectification model applied to QuickBird images. Proceedings of the IGARSS-International Geoscience and Remote Sensing Symposium, 29472950.

Robertson B. (2003) - Rigorous geometric modeling and correction of QuickBird imagery. Proceedings of the IGARSS-International Geoscience and Remote Sensing Symposium, 


\section{2: 797-802.}

Toutin T. (2001) - Geometric processing of IKONOS Geo images with DEM. Proceedings of ISPRS Joint Workshop High Resolution from Space.

Toutin T. (2004a) - Geometric processing of remote sensing images: model, algorithms and methods (review paper). ISPRS International Journal of Remote sensing, 25: 18931924.

Toutin T. (2004b) - GCP requirement for high resolution satellite mapping. Proceedings of ISPRS Congress, 35: 836-839.

Received 31/01/2010, accepted 26/05/2010. 